\title{
PENGEMBANGAN PENDIDIKAN ISLAM DALAM PENGARUH KONSEP AKAL
}

\author{
Siti Muntamah \\ Email: muntamahst84@yahoo.com \\ Dosen Pendidikan Agama Islam (PAI) Universitas Sumatera Selatan \\ Jalan. Jend. Sudirman, Kemuning. Palembang Sumatera Selatan
}

\begin{abstract}
ABSTRAK
Pendidikan pengembangan akal menjadi salah satu tujuan antara pendidikan, yakni ahdâf al-aqliyyah. Pendidikan pengembangan akal pada akhirnya akan berakumulasi dengan pendidikan pengembangan jasmani dan ruhani untuk mencapai tujuan akhir pendidikan Islam, yakni insân kâmil (manusia seutuhnya) yang mempunyai kesadaran, pemahaman, dan pengamalan akan posisi dirinya di antara Allah, alam, dan sesama manusia, serta mampu menjadi khalifah dan 'abd Allah. Dalam Islam, akal mendapat posisi yang signifikan, baik dalam pengembagan individu, masyarakat, maupun pengetahuan, terutama sains. Ia diposisikan sebagai hidayat al-'aqliyyah, yakni hidayah Allah yang hanya diberikan kepada manusia. Dengan akal, manusia mampu memahami symbol-simbol, hal-hal yang abstrak, menganalisis, membandingkan, maupun membuat kesimpulan dan akhirnya mampu membedakan antara yang benar (haq) dan salah (bathil).
\end{abstract}

Kata Kunci: Pendidikan Islam, Konsep Akal, Pengaruhnya

\section{PENDAHULUAN}

Akal memiliki kedudukan yang sangat tinggi dan mulia sekali di dalam Islam. Dengan akal maka terselamatlah diri daripada mengikuti hawa nafsu yang sentiasa menyuruh untuk melakukan keburukan. Dan setiap perbuatan buruk adalah yang akan membawa manusia ke Neraka Jahannam, Allah berfirman:

Dan mereka berkata: "Sekiranya kami mendengarkan atau memikirkan (peringatan itu) niscaya tidaklah kami termasuk penghuni-penghuni neraka yang menyala-nyala". [Q.S. Al-Mulk: 10]

Ayat ini menerangkan tentang penyesalan para penghuni neraka yang tidak mau mendengar dan menggunakan akal ketika hidup di dunia. Berarti, kedudukan akal sangat tinggi dan mulia sekali; yaitu mampu memelihara manusia dari api neraka.

Islam adalah agama yang sangat memperhatikan peran dan fungsi akal secara optimal, sehingga akal dijadikan sebagai standar seseorang diberikan beban taklif atau sebuah hukum. Jika seseorang kehilangan akal maka hukum-pun tidak berlaku baginya. Saat itu dia dianggap sebagai orang yang tidak terkena beban apapun.

Di dalam Islam, dalam menggunakan akal mestilah mengikuti kaidah-kaidah yang ditentukan oleh wahyu supaya akal tidak terbabas, supaya akal tidak digiring oleh 
kepentingan, sehingga tidak menghalalkan yang haram dan mengharamkan yang halal, sehingga tidak menjadikan musuh sebagai kawan dan kawan pula sebagai musuh.

Hai orang-orang yang beriman, janganlah kamu ambil menjadi teman kepercayaanmu orang-orang yang di luar kalanganmu (kerana) mereka tidak henti-hentinya (menimbulkan) kemudharatan bagimu. Mereka menyukai apa yang menyusahkan kamu. Telah nyata kebencian darpadai mulut mereka, dan apa yang disembunyikan oleh hati mereka lebih besar lagi. Sungguh telah Kami terangkan kepadamu ayat-ayat (Kami), jika kamu memahaminya (dengan menggunakan akalmu). [Q.S. Ali 'Imran :118]

Meskipun demikian, akal bukanlah penentu segalanya. Ia tetap memiliki kemampuan dan kapasitas yang terbatas. Oleh karena itulah, Allah SWT menurunkan wahyu-Nya untuk membimbing manusia agar tidak tersesat. Di dalam keterbatasannya-lah akal manusia menjadi mulia. Sebaliknya, ketika ia melampaui batasnya dan menolak mengikuti bimbingan wahyu maka ia akan tersesat.

\section{HASIL PEMBAHASAN}

\section{A. Peran Pendidikan Islam dalam Pengembangan Akal}

Manusia menurut Al-Qur'an merupakan ciptaan Allah, yang terdiri dari unsur jasmani, akal, dan ruhani. Ketiga unsur ini merupakan satu kesatuan yang tak terpisahkan, sekalipun secara substansial dapat dibedakan. Dalam proses kehidupan, manusia tidak dapat menanggalkan salah satu dari ketiganya, atau pun hanya memprioritaskan salah satu dari ketiganya. Dengan demikian, ketiga unsur pembentuk manusia tersebut memiliki posisi sama pentingnya, Oleh karenanya ketiganya harus dikembangkan secara seimbang, terintegrasi, dan proporsional, agar manusia mampu menjalani kehidupan sebagai khalifah dan 'abd Allah secara seimbang dan proporsional.

Salah satu unsur dari hakikat manusia adalah akal. Dalam bahasa Indonesia akal berarti daya pikir, pikiran dan ingatan, sedangkan dalam bahasa Arab akal ('aql) berarti akal pikiran, hati, ingatan, daya pikir, faham, diyat, benteng atau tempat berlindung. Dalam bahasa inggris akal barangkali tepat jika diterjemahkan sebagai kata intellect, intelegensia atau cognition (knowing; awareness; including sensation but exluding emotion).

Secara fisik, dalam bahasa Indonesia, akal sering diidentikkan dengan "otak" atau mind, yang diasumsikan tempatnya di kepala. Namun, menurut Harun Nasution, akal tidak persis sama dengan pengertian "otak", karena kalau otak, dalam artian fisik, maka hewan-hewan pun mempunyai otak. Akal merujuk pada daya nalar, daya pikir, dan daya kritis yang terdapat dalam jiwa manusia. Raghib al-Asfahani member pengertian akal sebagai energi potensial yang difungsikan manusia untuk menerima pengetahuan dan ilmu. Dengan demikian, ia merujuk pada fungsi dan kerja dari "otak-fisik" dan jiwa. Pendapat serupa dikemukakan pula oleh al-Ghazali dan Syed Naguib al-Attas. 
Dalam Islam, akal mendapat posisi yang signifikan, baik dalam pengembagan individu, masyarakat, maupun pengetahuan, terutama sains. Ia diposisikan sebagai hidayat al-'aqliyyah, yakni hidayah Allah yang hanya diberikan kepada manusia. Dengan akal, manusia mampu memahami symbol-simbol, hal-hal yang abstrak, menganalisis, membandingkan, maupun membuat kesimpulan dan akhirnya mampu membedakan antara yang benar (haq) dan salah (bathil).

Dalam sebuah hadits disebutkan bahwa "al-Islam huwa al-'aqlu, la dina liman la 'aqla lahu" (Islam adalah merupakan agama Ilmu dan agama akal (rasional); tidak ada kewajiban beragama (Islam) bagi mereka yang tidak mempunyai akal). Karena penghargaan akan eksistensi akal, Islam selalu mendorong umatnya untuk mempergunakan akal dalam berbagai dimensi kehidupan, termasuk dalam upaya mencari ilmu. Karena akal pula lah, manusia disebut sebagai makhluk homo sapiens, yaitu makhluk yang mempunyai fitrah dan kemampuan untuk berilmu-pengetahuan. Dengan akal itulah, manusia selalu ingin mengetahui apa yang ada di sekitarnya, lalu ia berfikir, memahami, dan menjadikannya sebagai pengetahua, baik bersifat teoritis maupun praktis.

Dalam Al-Qur'an, akal merupakan salah satu aspek penting dari esensi (hakikat) manusia, sebagaimana dijelaskan dalam banyak tempat di dalam Al-Qur'an. Sedangkan, Sa'id Ismail 'Aly dan Harun Nasution menjelaskan bahwa terdapat tujuh kata yang digunakan Al-Qur'an untuk mewakili konsep akal, yakni nazara, tadabbara, tafakkara, faqiha, tadzakkara, fahima, dan 'aqala. Dari ketujuh term di atas, penggunaan term yang mendekati kata akal, dalam bentuk kata benda dalam Bahasa Indonesia, adalah term yang ke-7. Abdul Fattah Jalal menyebutkan bahwa kata akal tidaklah pernah muncul dalam bentuk kata benda (ism) melainkan dalam bentuk kata kerja (fi'il). Kata kerja 'aqala menghasilkan derivasinya yakni 'aqaluhu, ta'qiluna, na'qilu, ya'qiluna, dan ya'qiluh. Selain ketujuh term di atas, terdapat beberapa term lain yang diasumsikan juga terkait dengan kerja dan fungsi akal, yakni yarauna, yabhatsun, yazkurun, yata'ammalun, ya'lamuna, yudrikuna, ya'rifuna, dan yaqrauna.

Abdullah Fattah Jalal menyebutkan bahwa selain term akal ditunjukkan oleh alQur'an dengan penunjukan yang cukup banyak pada proses, al-Qur'an pun, menggunakan kata albâb (jamak dari $a l-l u b$ ) yang juga bermakna akal. Kata ini muncul dalam al-Qur'an dalam 16 tempat. Misalnya dalam QS. Ali Imran [3]:190. Ketika manusia dilahirkan ke dunia ini, akal, termasuk juga jasmani dan ruhani, masih bersifat potensi (fitrah). Ia merupakan potensi nalar, daya fikir, atau proses pikiran yang lebih tinggi yang berkenaan dengan pengetahuan, daya akal budi, kecerdasan berfikir, atau boleh juga berarti terpelajar. Sebagai potensi, ia harus ditumbuh-kembangkan, dilatih, dan dibiasakan agar mampu bekerja atau berfungsi secara maksimal dan optimal. Di sinilah pendidikan pengembangan akal mempunyai peran signifikan sebagai fannu tasykil wa shina'at uqul al-insan (seni pembentukan atau rekayasa akal manusia). 'Ali Muhammad Madkur menyebutnya sebagai tarbiyyat al-thâqât al'aqliyyah. Pendidikan ini dimaksudkan untuk membentuk, membimbing, dan melatih kerja dan fungsi akal agar berfungsi secara maksimal dan optimal, serta sesuai dengan fitrah, maksud, dan tujuan penciptaannya. Pada sisi lain, akal pun harus diatur, 
dikendalikan, dan dievaluasi agar fungsi dan kerjanya tidak menyalahi tata aturan yang ditetapkan oleh Allah swt, sebagai Pencipta-nya. Misalnya, al-Qur'an dalam QS alAn'am 116, menyebutkan salah satu kelemahan akal, yakni mengikuti prasangka (dzan).

Dengan demikian, pendidikan pengembangan akal menjadi salah satu tujuan antara pendidikan, yakni ahdâf al-aqliyyah. Pendidikan pengembangan akal pada akhirnya akan berakumulasi dengan pendidikan pengembangan jasmani dan ruhani untuk mencapai tujuan akhir pendidikan Islam, yakni insân kâmil (manusia seutuhnya) yang mempunyai kesadaran, pemahaman, dan pengamalan akan posisi dirinya di antara Allah, alam, dan sesama manusia, serta mampu menjadi khalifah dan 'abd Allah.

Sebagai sumber ilmu, apabila diteliti lagi dari uraian intelek di atas, maka akan didapati banyak tingkatan dalam pendapatan ilmu. Sebab, pada akal ada sisi-sisi yang terluar dan terdalam. Yang terdalam dari akal erat hubungannya dengan intuisi dan wahyu, dan ilmu yang dihasilkan juga berkaitan dengan hal tersebut. Sedangkan bagian terluar erat hubungannya dengan aspek panca indera manusia yang juga menghasilkan ilmu yang empirik-rasional.

Dilihat dari istilahnya, yakni sebagai kekuatan manusia untuk bernalar, maka akal dalam klasifikasi ilmu yang dikonseptualisasikan al-Attas menghasilkan ilmuilmu 'aqli. Menurutnya, ilmu yang berdasarkan akal adalah sains filosofis, rasional dan intelektual, yang meliputi sains kemanusiaan (human sciences), sains tabii (natural sciences), sains terapan (applied sciences) dan teknologi.

Dalam konsep pendidikannya, ilmu-ilmu dalam klasifikasi ini termasuk ilmu yang fardhu kifayah. Artinya, ilmu ini tidak harus masing-masing orang menguasainya. Fardhu kifayah adalah amalan yang wajib dikerjakan namun kewajiban itu akan gugur apabila sudah dilaksanakan oleh sebagian. Ini bisa diartikan bahwa untuk ilmu-ilmu di bawah akal ini hendaknya manusia berbagi tugas, tidak semestinya seragam. Semakin beragama bidang yang dikuasai masyarakat, maka semakin tinggi kualitas masyarakat itu. Berbeda dengan fardhu kifayah yang cukup diemban oleh sebagian orang saja, ilmu fardhu 'ain harus diemban oleh setiap individu. Ini dalam falsafah pendidikan al-Attas adalah ilmu-ilmu yang dibawah wahyu, yaitu ilmu-ilmu seperti al-Quran, Sunnah, Shariah, Tauhid, Tasawwuf, dan bahasa Arab. Menurutnya, semua orang Islam harus mengerti ini dan hukumnya wajib bagi tiap individu.

Klasifikasi ilmu al-Attas kepada fardhu ain dan fardhu kifayah diambilkan dari skemanya tentang konsep manusia, ilmu dan universitas, sebagaimana berikut: pertama, manusia yang meliputi jiwa dan entitas dalaman (ruh, nafs, qalb, 'aql) dan badan dan fakultas-fakultas fisiknya; kedua, ilmu yang terdiri dari ilmu pemberian Tuhan dan ilmu yang didapatkan oleh manusia; ketiga, universitas yang meliputi ilmuilmu fardu ain dan kifayah. Dalam skema itu, posisi The God-given Knowledge berada di atas dan the acquired knowledge berada di bawah. Sepertinya posisi ini penting dalam pandangan al-Attas. Sebab, posisi di atas menunjukkan itu adalah tinggi dan terhormat. Dan menurutnya, posisi yang di atas ini merujuk kepada fakultas dan sensasi spiritual manusia. Sedangkan posisi di bawahnya menunjukkan kepada fakultas dan sensasi fisikal manusia. Menariknya, al-Attas memposisikan intelek ('aql) sebagai 
penghubung antara bagian fisikal dan spiritual itu. Dengan alasan bahwa 'aql pada kenyataannya merupakan substansi spiritual, seperti yang dijabarkan sebelumnya, yang memungkinkan manusia untuk mengerti realitas dan kebenaran spiritual.

\section{B. Hubungan akal dan Otak}

Didalam setiap diri manusia diberi satu anugrah oleh Tuhan yaitu Otak yang akan berguna bagi kelangsungan hidup manusia itu sendiri. Otak diberikan oleh tuhan kepada manusia supaya manusia itu bisa memecahkan masalah-masalah yang terjadi di muka bumi ini, karena semakin hari semakin berat permasalahan yang terjadai di dunia ini. Otak juga terbagi 2 yaitu otak kiri dan otak kanan. Fungsi otak kiri berkaitan dengan logika, angka, tulisan, kecerdasan, hitungan, analisa, dan untuk ingatan jangka pendek. Sedangkan otak kanan kita diguakan untuk kreativitas, imajinasi, musik, warna, bentuk, emosi dan untuk ingatan jangka panjang

Setiap manusia memiliki kecenderungannya masing-masing dalam penggunaan otak kanan atau otak kiri, baik sadar ataupun dibawah sadarnya. Hal ini bergantung pada banyak faktor yang mempengaruhinya sejak masih kecil bahkan sejak dalam kandungan. Kecenderungan berpikir dengan otak kanan ataupun kiri merupakan hasil dari suatu proses yang sangat panjang dan yang tak boleh kita lupakan adalah kecenderungan ini adalah suatu berkah ciptaan Tuhan Yang Maha Esa.

Setiap manusia memang diberikan otak oleh tuhan tetapi tidak semua manusia mendapat kan otak yang cerdas. Otak yang cerdas dapat diperoleh dari kita sendiri dengan cara banyak belajar,dan berdiskusi. Melalui cara itu dapat kita tingkatkan daya ingat otak kita. Kita tau apabila otak kita tidak dilatih secara terus menerus maka otak kita itu bisa tumpul dan tidak bisa dipakai untuk berfikir, apalagi berfikir dengan serius, maka itu sering-sering lah latih otak kita dari hala-hala yang berguna.

Didalam komponen otak ada yang namanya akal dan pikiran yang menelaah setiap permasalahan-permasalahn yang terjadi. Akal adalah penuntun kita ditengahtengah segala kenyataan yang ada,tapi akal sendiri tidak dapat memperhintungkan segalah sesuatu dari apa yang terlihat. Akal juga bisa berarti jalan atau cara melakukan sesuatu, daya upaya, dan ikhtiar. Akal dan pikiran juga bermanfaat sebagai pengigat dan sebagai berfikir.

Kebanyakan kita mengatakan bahwa akal itu adalah otak, sehingga kalau kita berkata kepada orang lain "gunakan akalmu!" maka kita akan menunjuk dan mengarahkannya kepada kepala kita sebagai isyarat bahwa tempatnya akal disana. Ketahuilah wahai saudaraku akal bukanlah otak, jadi letak keberadaannya bukan di kepala. Keberadaan akal tidaklah berbentuk secara fisik sehingga tidak dapat dilihat oleh mata kepa ini. Tapi meskipun demikian, fungsi dan gerakannya dapat dirasakan.

Setiap dari kita tentu saja dapat menyeslesaikan setiap masalah yang kita hadapi dengan cara berpikir, menemukan sebuah solusi yang tepat yang dapat membawa kita keluar dari lingkaran permasalahan yang kita hadapi, itu lah akal pikiran. Setiap dari kita tentu saja dapat menyeslesaikan setiap masalah yang kita hadapi dengan cara berpikir, menemukan sebuah solusi yang tepat yang dapat membawa kita keluar dari lingkaran permasalahan yang kita hadapi, itu lah akal. 
Bicara tentang otak dan akal, Al-Qur'an memiliki cakupan yang luas tentang akal dan otak, seperti pada ayat berikut ini :

"(Orang yang berakal adalah) orang-orang yang mengingat (yadzkuruna) Allah sambil berdiri atau duduk atau dalam keadaan berbaring dan mereka berpikir (yatafakkaruna) tentang penciptaan langit dan bumi (seraya berkata): "Ya Tuhan kami, tiadalah Engkau menciptakan ini dengan sia-sia. Maha Suci Engkau, maka peliharalah kami dari siksa neraka," [QS. Al-Imraan: 190-191].

Lebih jauh lagi Al-Qur'an menjelaskan bahwa orang-orang yang berakal adalah orang-orang yang memadukan fungsi antara pikiran (Cortex) dan perasaan (sistem limbik) secara maksimum, sehingga ketika memperoleh keyakinan (kesimpulan tertinggi berupa keimanan) bakal menggetarkan jantung-hati (Qalb), yang berada di dalam dada.

Bahkan ilmuwan-ilmuwan muslim yang merujuk pada kitab suci Al-qur'an , dijelaskannya bahwa di dalam otak manusia terdapat Cortex Cerebri, atau sering disebut Cortex saja. Sangat menarik mendapati kenyataan bahwa pusat penglihatan dan pendengaran manusia ternyata juga terdapat di Cortex-nya. Pusat penglihatan berada di kulit otak bagian belakang, sedangkan pusat pendengaran berada di bagian samping. Berarti, proses melihat dan mendengar itu sebenarnya identik dengan proses berpikir. Orang yang melamun, meskipun bisa melihat dengan mata dan mendengar dengan telinga, dia tidak bisa memahami apa yang sedang dilihat dan didengarnya. Pada saat demikian, dia tidak sedang mengaktifkan daya pikir Cortexnya secara utuh.

\section{Hubungan akal dan Nafsu Manusia}

Ada tiga golongan manusia berdasarkan pada akal dan nafsunya yaitu:

1. Manusia yang nafsunya lebih dominan daripada akalnya.

2. Manusia yang nafsu dan akal sama-sama dominan.

3. Manusia yang akalnya lebih dominan daripada nafsunya.

Manusia golongan pertama, Akan cenderung menuruti keinginan hawa nafsunya. Segala sesuatu didasarkan hanya kepada nafsu semata. Nafsu akan cenderung memegang kendali penuh terhadap akalnya, bahkan aturan negara dan agama pun akan dilawannya bila tidak sesuai dengan kriteria nafsunya.

Secara umum, nafsu ini akan cenderung membawa manusia pada perbuatan yang negatif karena dominasinya terhadap akal. Manusia dalam golongan ini tidak akan pernah punya perasaan bersalah.

Manusia golongan kedua, Manusia yang kadang berbuat atau bertindak berdasarkan akal pada suatu kesempatan dan berdasarkan nafsu pada kesempatan lainnya. Ia akan bisa berbuat baik di suatu kesempatan dan berbuat jahat di kesempatan lainnya.

Ketika telah melakukan perbuatan jahat, ada kemungkinan akan timbul rasa bersalah dalam dirinya dan timbul hasrat untuk memohon ampunan. Namun demikian, ada kemungkinan ia akan mengulangi lagi perbuatan jahatnya di waktu yang lain. 
Manusia golongan ketiga, Manusia yang cenderung berbuat baik di setiap kesempatan. Ini adalah kondisi ideal manusia, dimana akal mampu mengendalikan nafsu dan membawanya pada hal-hal yang positif sesuai dengan peraturan negara dan agama.

Tidak ada yang lain, selain manusia belajar manggunakan akalnya, belajar mengendalikan nafsunya, disisi lain manusia juga harus belajar menerima segala kemungkinan yang terjadi, yang baik ataupun yang buruk. Dan itu merupakan hal yang paling bijak yang dapat dilakukan manusia. Dan yang pasti adalah bahwa segala yang terjadi dalam kehidupan manusia adalah yang terbaik menurut ketentuan Allah SWT.

Akal memainkan peran penting dalam membatasi dan mengendalikan hawa nafsu manusia. la juga berperan mem antu manusia agar tidak selalu memenuhi segala ajakan nafsunya.

Kata 'aql atau 'iqâl dalam bahasa Arab mempunyai arti 'ikatan' dan 'pembatasan'. Dan begitulah peran yang harus diambil akal dalam menghadapi hawa nafsu manusia.

Peran yang dimainkan akal dalam kehidupan manusia ialah menahan dan membatasi gerak laju hawa nafsu serta mencegah sikap ekstremis dalam memenuhi segala tuntutan hawa nafsu.

Besar kesempurnaan dan kekuatan akal, sebesar taufik yang dimiliki manusia dalam mengendalikan gerak hawa nafsu.

Akal dan hawa nafsu sania-sama berperan vital dalam hidup manusia. Hawa nafsu memotori siklus hidup manusia, sedang akal berperanan sensitif dalam membatasi, mengen dalikan, serta mencegah hegemoni dan perusakan hawa nafsu atas totalias manusia.

\section{KESIMPULAN}

1. Pendidikan pengembangan akal menjadi salah satu tujuan antara pendidikan, yakni ahdâf al-aqliyyah. Pendidikan pengembangan akal pada akhirnya akan berakumulasi dengan pendidikan pengembangan jasmani dan ruhani untuk mencapai tujuan akhir pendidikan Islam, yakni insân kâmil (manusia seutuhnya) yang mempunyai kesadaran, pemahaman, dan pengamalan akan posisi dirinya di antara Allah, alam, dan sesama manusia, serta mampu menjadi khalifah dan 'abd Allah.

2. Dalam Islam, akal mendapat posisi yang signifikan, baik dalam pengembagan individu, masyarakat, maupun pengetahuan, terutama sains. Ia diposisikan sebagai hidayat al-'aqliyyah, yakni hidayah Allah yang hanya diberikan kepada manusia. Dengan akal, manusia mampu memahami symbol-simbol, hal-hal yang abstrak, menganalisis, membandingkan, maupun membuat kesimpulan dan akhirnya mampu membedakan antara yang benar (haq) dan salah (bathil)

3. Didalam komponen otak ada yang namanya akal dan pikiran yang menelaah setiap permasalahan-permasalahn yang terjadi. Akal adalah penuntun kita ditengah-tengah segala kenyataan yang ada, tapi akal sendiri tidak dapat memperhintungkan segalah sesuatu dari apa yang terlihat. Akal juga bisa berarti jalan atau cara melakukan 
sesuatu, daya upaya, dan ikhtiar. Akal dan pikiran juga bermanfaat sebagai pengigat dan sebagai berfikir.

4. Akal dan hawa nafsu sama-sama berperan vital dalam hidup manusia. Hawa nafsu memotori siklus hidup manusia, sedang akal berperanan sensitif dalam membatasi, mengen dalikan, serta mencegah hegemoni dan perusakan hawa nafsu atas totalias manusia

\section{DAFTAR PUSTAKA}

A. Tafsir, 2008, Filsafat Pendidikan Islami, Bandung: Rosda Karya.

Abdullah Fatah Jalal, Azas-Azas Pendidikan Islam, Bandung: CV Diponegoro.

Abdurrahman Saleh Abdullah, 2007, Teori-Teori Pendidikan Berdasarkan al-Qur'an , Jakarta: Rineka Cipta.

Ahmad Warson Munawwir, Al-Munawwir: Qamus 'Araby-Indonesia, Yogyakarta: Krapyak.

Al-'Allamah Raghib al-Asfahani, Mu'jam Mufradat Alfadz al-Qur'an, Beirut: Dar alFikr.

Al-Attas (1986), A Commentary on The Hujjat al-Siddiq of Nur al-Din al-Raniri, Kuala Lumpur: Ministry of Culture of Malaysia, 293.

Ali Ahmad Madkur, 2002, Manhaj al-Tarbiyyah fi al-Tashawwur al-Islami, Kairo: Dar al-Fikr a'-'Araby.

Ali Ahmad Madkur, 2002, Manhaj al-Tarbiyyahfi al-Tashawwur al-Islâmi, Kairo: Dar al-Fikr al-'Arabi,

Harun Nasution, 1982, Akal dan Wahyu Dalam Islam, Jakarta: UI Press.

http://www.alhassanain.com/indonesian/book/book/ethics_and_supplication/ethics_b ooks/hawa nafsu/007.html di akses kamis tanggal 28 September 2016.

Ismail Raji al-Faruqi, 1984, Tauhid, Bandung: Pustaka.

Jalaluddin, 2003, Teologi Pendidikan, Jakarta: Rajawali Press.

Muhammad 'Ali al-Khuli, 1981, Qamus al-Tarbiyyah: English-'Araby, Beirut: Dar 'al'Ilm li al-Malayin.

Omar Mohammad al-Toumy al-Syaibani, Falsafah Pendidikan Islam. Jakarta: Bulan Bintang.

Sa'id Isma'il 'Aly, 2007, Ushul al-Tarbiyyah al-Islamiyyah, Kairo: Dar al-Salam.

Syed Naguib al-Attas, 1986, Konsep Pendidikan Islam, Bandung: Mizan.

Zakiyah Daradjat, 1989, Ilmu Jiwa, Jakarta: Bulan Bintang. 